\title{
British Thermal Unit Mean
}

National Cancer Institute

\section{Source}

National Cancer Institute. British Thermal Unit Mean. NCI Thesaurus. Code C69154.

A non-SI unit of energy equal to $1 / 180$ of the amount of heat required to raise the temperature of one pound avoirdupois of air-free water from 32 to 212 degrees

Fahrenheit at a constant pressure of one atmosphere. Mean British thermal unit is equal to $1.05587 \mathrm{~kJ}$. 